\title{
CHANGES IN THE LEVEL OF a1-ANTITRYPSIN IN PATIENTS WITH NON-ALCOHOLIC FATTY LIVER DISEASE
}

D0I: 10.36740/WLek202003119

\author{
Yelyzaveta S. Sirchak, Vasilij I. Griga, Nelli V. Bedey, Ivan I. Pushkash \\ STATE HIGHER EDUCATIONAL INSTITUTION «UZHHOROD NATIONAL UNIVERSITY», MEDICAL FACULTY, UZHHOROD, UKRAINE
}

\begin{abstract}
The aim: To investigate changes in the level of a1-antitrypsin (A1AT) in blood and in stool and their diagnostic value in patients with NAFLD and with impaired carbohydrate metabolism at different stages of liver damage.

Materials and methods: 34 patients with non-alcoholic fatty hepatosis (NAFH) and 40 patients with non-alcoholic steatohepatitis (NASH) were examined. Enzyme-linked immunosorbent assay for all patients with serum and coli was performed by determining the level of A1AT.

Results: In patients with NAFLD, in combination with IR, the level of A1AT in the blood plasma is only 1.6 times higher than that of the control group ( $p<0.05)$, and in the case of combination of NAFH and type 2 diabetes mellitus (T2DM) - it is 2 times higher $(p<0.05)$. In patients with NASH in combination with insulin resistance (IR), the level of A1AT in the serum was 4.1 times higher than in the control group, and for NASH and type 2 diabetes -4.2 times.

Conclusions:The level of A1AT in the blood plasma increases proportionally to the degree of progression of liver damage (from the minimum values at NAFH to the maximum at NASH), regardless of the type of carbohydrate metabolism disturbance. The combination of NAFLD and T2DM is accompanied by a more pronounced increase in A1AT in stool and a1-antitrypsin clearance than the combination of NAFLD and IR.
\end{abstract}

KEY WORDS: non-alcoholic fatty liver disease type, 2 diabetes mellitus, insulin resistance, a1-antitrypsin

Wiad Lek. 2020;73(3):508-511

\section{INTRODUCTION}

Non-alcoholic fatty liver disease (NAFLD) is prevalent worldwide and is the most common chronic liver disease in Western countries. Its increasing prevalence is associated with major risk factors such as obesity, dyslipidemia, type 2 diabetes mellitus (T2DM), and the metabolic syndrome [1]. NAFLD is a systemic disorder of energy, glucose, and lipid homeostasis with hepatic manifestations [2]. Metabolic disorders, such as lipid accumulation, insulin resistance (IR), and inflammation, have been implicated in the pathogenesis of NAFLD, but the underlying mechanisms, including those that drive disease progression, are not fully understood [3].

Alpha-1 Antitrypsin (A1AT) is a highly polymorphic serum protein. Several genetic variants are associated with varying degrees of decreased serum levels; however, these levels can rise in response to infection, inflammation, injury and estrogen levels. Although the effect of inflammation is well established, it has never been studied quantitatively with respect to specific genotypes in a large representative sample [4]. A1AT is a circulating liver derived protease inhibitor [5]. Despite A1AT well-known involvement in hepatic fibrosis, its role in NAFLD pathogenesis is not well characterized.

\section{THE AIM}

To investigate changes in the level of a1-antitrypsin in blood and in stool and their diagnostic value in patients with NAFLD and with impaired carbohydrate metabolism at different stages of liver damage.

\section{MATERIALS AND METHODS}

At the clinical site of the department of propaedeutic of internal diseases of the medical faculty of SHEI "UzhNU" (gastroenterology and endocrinology department of the TRCH n. a. A. Novak) during 2016-2019, 74 patients with NAFLD were examined. The average age was $47.8 \pm 7.9$ years. Patients were divided into Groups, namely:

- Group I included 34 patients with non-alcoholic fatty hepatosis (NAFH) (among them there were 20 males (58.8\%) and 14 females (41.2\%), the average age was $47.7 \pm 6.8$ years)

- Group II included 40 patients with non-alcoholic steatohepatitis (NASH) (among them there were 24 males $(60.0 \%$ ) and 16 females (40.0\%), the average age was $48.9 \pm 6.8$ years) In order to achieve the aim of the research, the patients were further divided into subgroups depending on the presence of type 2 diabetes (moderately severe) or insulin resistance (IR).

The NAFH group $(\mathrm{n}=34)$ was divided as follows: 1.1 had 16 patients with insulin resistance (IR) and 1.2 had 18 patients with type 2 diabetes (T2DM).

Group II $(\mathrm{n}=40)$ with NASH patients was divided as follows: 2.1 included 20 patients with insulin resistance (IR) and 2.2 had 20 patients with type 2 diabetes (T2DM). 
The control group included 20 practically healthy persons (12 males $(60.0 \%)$ and 8 females $(40.0 \%)$ ), the average age was $47.6 \pm 5.8$ years.

All studies were performed with patients consent (written consent for performing appropriate diagnostic and therapeutic measures was received from all of the patients), and the methodology of their implementation were in line with the Helsinki Declaration of Human Rights of 1975 and its 1983 revised version, and in line with Europe Convention on Human Rights, as well as biomedicine and legislation of Ukraine.

All the examined patients were subject to general clinical, anthropometric, instrumental, and laboratory tests. To verify the diagnosis, attention was paid to the nature of complaints, as well as the history of the disease. In anthropometric study, height, weight, waist circumference were determined, and body mass index (BMI) was calculated.

Ultrasound examination of the abdominal cavity was performed on all patients according to generally accepted method. Standard and biochemical blood serum tests have been performed to determine the functional state of the liver, lipid metabolism indexes and carbohydrate metabolism (glucose, insulin, glycosylated hemoglobin (HbA1c, \%) indexes.

NAFLD diagnosis was established in accordance with the Unified Clinical Protocol criteria (Order of the Ministry of Health of Ukraine dated November 6, 2014, No. 826) and EASL-EASD-EASO Clinical Recommendations for Diagnosis and Treatment of NAFLD [6].

The degree of liver damage has been calculated using surrogate markers of fibrosis with the help of online calculators: NAFLD fibrosis score (NFS), Fibrosis 4 calculator (FIB-4), Fibrotest.

Insulin resistance was determined using the HOMA-IR (homeostasis model assessment method for insulin resistance), which was calculated according to this formula (normally HOMA-IR $-<2.5$ ):

HOMA = blood insulin serum on an empty stomach $(\mu \mathrm{U} / \mathrm{mL}) \times$ blood plasma glucose on an empty stomach $(\mathrm{mmol} / \mathrm{L}) / 22.5$

Diagnosis of type 2 diabetes mellitus has been established according to IDF recommendations (2005), as well as taking into account the criteria of unified clinical protocol (Order of Ministry of Health of Ukraine dated December 21, 2012, No. 1118) [7]. Level of severity of T2DM was evaluated according to the HbA1c (norm being up to $6.0 \%$ ).

Enzyme-linked immunosorbent assay for all patients with serum and coli was performed by determining the level of a 1-antitrypsin, using the test system of Immundiagnostic AG (Germany). Clearance of $\alpha 1$-antitrypsin was calculated based on the results of the assay.

The criteria for exclusion of patients from the study were also: type 1 diabetes, type 2 diabetes (moderate to severe degrees, with severe manifestations of diabetic angioneuropathy), chronic hepatitis, alcoholic, viral (hepatitis B, C, D) etiologies, autoimmune hepatitis.

The analysis and processing of the patient examination results were carried out using the computer program
"Statistics" for Windows v.10.0 (StatSoft Inc., USA) using parametric and nonparametric methods of evaluating the results obtained.

\section{RESULTS}

It should be noted severe disruptions of carbohydrate metabolism when combined with type 2 diabetes or IR with NAFLD. In this case, the maximum deviations from the parameters of the control group is established in patients Subgroups 1.1 (NAFH in combination with IR) - tables I.

Changes of $\alpha 1$-antitrypsin in patients with NAFLD by subgroups depending on the type of carbohydrate metabolism disorders are presented in table II.

The results of our study showed that in patients with NAFLD, the index of al-antitrypsin in blood plasma is significantly increased, compared with its level in healthy persons. It should be noted that in patients with NAFLD, in combination with IR, the level of A1AT in the blood plasma is only 1.6 times higher than that of the control group ( $\mathrm{p}<0.05$ ), and in the case of combination of NAFH and type 2 diabetes - it is 2 times higher $(p<0.05)$. In patients with NASH in combination with IR, the level of A1AT in the serum was 4.1 times higher than in the control group ( $\mathrm{p}<0.01)$, and for NASH and type 2 diabetes -4.2 times $(\mathrm{p}<0.01)$.

When characterizing changes in A1AT levels in stool, in the patients we examined, we found more pronounced deviations from the norm when combining NAFLD and type 2 diabetes. Specifically, in patients in the 1.2 subgroup this indicator was increased to $30.90 \pm 0.76 \mathrm{mg} / \mathrm{dL}(\mathrm{p}<0.05)$, and in patients in the 2.2 subgroups - to $45.7 \pm 1.11 \mathrm{mg} /$ $\mathrm{dL}(\mathrm{p}<0.05)$.

Note the marked increase in A1AT clearance in patients with NASH and type 2 diabetes (up to $122.14 \pm 8.23 \mathrm{ml} /$ day $-\mathrm{p}<0.001$ ), as well as with NAFLD and type 2 diabetes (up to $88.16 \pm 0.45 \mathrm{ml} /$ day $-\mathrm{p}<0.01$ ). In patients with IR and liver damage, the clearance of A1AT was lower in both subgroups.

\section{DISCUSSION}

Therefore, in patients with NAFLD, both at the stage of $\mathrm{NAFH}$ and at the stage of NASH, an increase in the level of A1AT in the serum was established. It is known that A1AT is an inhibitor of proteolytic enzymes (trypsin, chymotrypsin, elastase, kallikrein, catapsin), and also indicates an inflammatory process in the body, including the liver. This is evidenced by a more pronounced increase in its level in patients examined at the stage of NASH.

Increased intestinal A1AT loss when combined with NAFLD with type 2 diabetes may indicate impaired intestinal mucosal permeability in these patients and indicate a systemic nature of the disease. Our results require further studies to understand the processes that occur in patients with combination of NAFLD and impaired carbohydrate metabolism. In the professional literature, the issue of the influence of disorders in the gut microbiocenosis on the formation of metabolic 
Table I. Changes of carbohydrate metabolism parameters in patients with NAFLD depending on presence of T2DM or IR

\begin{tabular}{cccccc}
\hline & & \multicolumn{3}{c}{ Participants in main with NAFLD } \\
\cline { 3 - 6 } Indicator & $\begin{array}{c}\text { Control } \\
\text { group }\end{array}$ & \multicolumn{2}{c}{ Group I $(\mathbf{n = 3 4 )}$} & \multicolumn{2}{c}{ Group II (n=40) } \\
\cline { 3 - 6 } & & $\begin{array}{c}\text { Subgroup 1.1 } \\
(\mathbf{n}=16)\end{array}$ & $\begin{array}{c}\text { Subgroup 1.2 } \\
(\mathbf{n}=18)\end{array}$ & $\begin{array}{c}\text { Subgroup 2.1 } \\
(\mathbf{n}=\mathbf{2 0})\end{array}$ & $\begin{array}{c}\text { Subgroup 2.2 } \\
(\mathbf{n}=\mathbf{2 0})\end{array}$ \\
\hline Glucose $(\mathrm{mmol} / \mathrm{L})$ & $4.51 \pm 0.41$ & $6.95 \pm 0,27^{*}$ & $7.95 \pm 0.24^{*}$ & $6.75 \pm 0.31^{*}$ & $7.87 \pm 0.19^{*}$ \\
\hline HbA1c, \% & $4.38 \pm 0.26$ & $6.88 \pm 0,36^{*}$ & $7.98 \pm 0.36^{*}$ & $6.80 \pm 0.36^{*}$ & $7.89 \pm 0.23^{*}$ \\
\hline Insulin (U/L) & $9.20 \pm 1.14$ & $44.7 \pm 6,5^{* *},+$ & $29.7 \pm 3.3^{* *}$ & $38.4 \pm 4.1^{* *},+$ & $21.3 \pm 1.7^{*}$ \\
\hline C-peptide (ng/mL) & $4.54 \pm 0.97$ & $21.77 \pm 2,31^{* *}$ & $14.56 \pm 1.45^{* *},+$ & $17.41 \pm 1.67^{* *}$ & $12.33 \pm 1.22^{* *},+$ \\
\hline HOMA-IR & $1.71 \pm 0.32$ & $12.81 \pm 3,26^{* *}$ & $10.41 \pm 2.9^{* *}$ & $11.32 \pm 2.78^{* *},+$ & $7.44 \pm 0.23^{* *}$ \\
\hline
\end{tabular}

Note: the difference between the indicators in patients of Group 1 and control group is significant - $^{*} p<0.05$; $^{* *}-p<0.01$; the difference between the indices in patients by subgroups is significant $-+-p<0.05 ;++-p<0.01$.

Table II. The content of a1-antitrypsin in blood plasma and in stool samples and its clearance in patients with NAFLD

\begin{tabular}{|c|c|c|c|}
\hline \multirow{2}{*}{ Patient groups } & \multicolumn{2}{|c|}{ Рівень а1-antitrypsin (mg/dl) } & \multirow{2}{*}{$\begin{array}{l}\text { a1-antitrypsin clearance } \\
\text { (mL/24hrs) }\end{array}$} \\
\hline & in blood plasma & in stool & \\
\hline Control group & $128.12 \pm 1.23$ & $15.83 \pm 0.19$ & $18.77 \pm 0.65$ \\
\hline \multicolumn{4}{|c|}{ I group ( $n=34)$ subgroups: } \\
\hline Subgroup $1.1(n=16)$ & $203.05 \pm 4.49^{*}$ & $18.26 \pm 1.02$ & $21.15 \pm 0.88$ \\
\hline Subgroup $1.2(n=18)$ & $256.17 \pm 4.45^{*}$ & $30.90 \pm 0.76^{*}$ & $88.16 \pm 0.45^{* *}$ \\
\hline \multicolumn{4}{|c|}{ Il group $(n=40)$ subgroups: } \\
\hline Subgroup $2.1(n=20)$ & $527.16 \pm 6.16^{* *}$ & $21.83 \pm 0.71$ & $44.21 \pm 2.18^{*}$ \\
\hline Subgroup $2.2(n=20)$ & $544.08 \pm 9.15^{* *}$ & $45.7 \pm 1.11^{*}$ & $122.14 \pm 8.23^{* * *}$ \\
\hline
\end{tabular}

Note: statistically significant difference was found between control group and patient groups: ${ }^{*}-p<0.05 ;{ }^{* *}-p<0.01 ;{ }^{* * *}-p<0.001$

diseases, including type 2 diabetes, IR, and NAFLD, is actively discussed. In our opinion, assessment of the barrier function of the intestine for its adequate correction, as well as therapy aimed at reducing inflammation in the liver and apparently in the intestine, should be a major element in the prevention of the progression of liver damage in its fatty disease and its combination with impaired carbohydrate metabolism .

\section{CONCLUSIONS}

1. In patients with NAFLD, increased levels of $\alpha 1$-antitrypsin in blood plasma and in stool have been established 2. The level of A1AT in the blood plasma increases proportionally to the degree of progression of liver damage (from the minimum values at NAFH to the maximum at $\mathrm{NASH}$ ), regardless of the type of carbohydrate metabolism disturbance (IR, T2DM).

3. The combination of NAFLD (NAFH, NASH) and type 2 diabetes is accompanied by a more pronounced increase in A1AT in stool and a1-antitrypsin clearance than the combination of NAFLD and IR.

\section{REFERENCES}

1. Lim H-W, Bernstein D. Risk Factors for the Development of Nonalcoholic Fatty Liver Disease/Nonalcoholic Steatohepatitis, Including Genetics. Clinics in Liver Disease. 2018; 22(1):39-57.

2. Pickett-Blakely 0, Young K, Carr RM. Micronutrients in Nonalcoholic Fatty Liver Disease Pathogenesis. Cellular and Molecular Gastroenterology and Hepatology. 2018; 6(4):451-462.
3. Kitade H, Chen G, Ni Y at al. Nonalcoholic Fatty Liver Disease and Insulin Resistance: New Insights and Potential New Treatments. Nutrients. 2017; 9(4): 387.

4. Sanders C L, Ponte A, Kueppers F. The Effects of Inflammation on Alpha 1 Antitrypsin Levels in a National Screening Cohort. COPD: Journal of Chronic Obstructive Pulmonary Disease. 2018; 15(1):10-16.

5. Abdel-Wahab R, Hassan M, Wolff R A et al. Association of elevated alpha-1 antitrypsin with advanced clinicopathologic features of hepatocellular carcinoma. Journal of Clinical Oncology. 2017; 4:289.

6. European Association for the Study of the Liver (EASL), European Association for the Study of Diabetes (EASD) and European Association for the Study of Obesity (EASO) EASL-EASD-EASO Clinical Practice Guidelines for the management of non-alcoholic fatty liver disease. Journal of Hepatology. 016; 64:1388-1402. doi.org/10.1016/j. jhep.2015.11.004.

7. Hobzej M, Matyuha L, Netjazhenko V et al. Type 2 Diabetes Mellitus. Adapted clinical guideline based on evidence. Kijiv; 2012, p. 343 (in Ukrainian). http://ukrgastro.com.ua/klinichni-protokoli-ta-nastanovi/

This scientific research is part of the State Higher Educational Establishment "UzhNU" medical faculty propaedeutics of internal diseases department state budgeted topic No. 851 "Mechanisms of formation of complications in liver and pancreas diseases, methods of their treatment and prevention" (state registration number $0115 \mathrm{U} 001103)$.

\section{ORCID and contributionship:}

Yelyzaveta S. Sirchak - 0000-0001-6738-0843 A, F Vasilij I. Griga - 0000-0003-3666-8910 B,D, E 
Ivan I. Pushkash - 0000-0002-5728-2980 ${ }^{B}$

Nelli V. Bedey 0000-0001-8044-0644 ${ }^{B, C}$

\section{Conflict of interest:}

The Authors declare no conflict of interest.

\section{CORRESPONDING AUTHOR}

\section{Yelyzaveta S. Sirchak}

«Uzhhorod national university», medical faculty,

Narodna sqr.3, Uzhhorod, Ukraine, 88000.

tel: +380509761794

e-mail:sirchakliza777@gmail.com

Received: 17.01 .2020

Accepted: 05.03 .2020

A - Work concept and design, B - Data collection and analysis, C - Responsibility for statistical analysis,

D-Writing the article, $\mathbf{E}$-Critical review, $\mathbf{F}$ - Final approval of the article 